\title{
LOCAL FRACTURE TOUGHNESS AND RESIDUAL STRESS MEASUREMENTS ON NiAI BOND COATS BY MICRO CANTILEVER AND FIB-BASED BAR MILLING TESTS
}

\author{
Ralf Webler, Markus Krottenthaler, Steffen Neumeier, Karsten Durst, Mathias Göken \\ Institut für Werkstoffwissenschaften, Lehrstuhl I, Universtität Erlangen-Nürnberg, Martensstrasse 5, D-91058 Erlangen, Germany
}

Keywords: Bond coat, NiAl, micro cantilever, residual stress, fracture toughness, FIB, thermal cycling, nanoindentation

\begin{abstract}
The mechanical behavior of bond coats depends on their chemical composition. Important for the mechanical behavior is the $\mathrm{Al}$ content of $\beta$-NiAl based coatings. Additionally, internal stresses are present and change during thermal cycling. Therefore bond coats with different $\mathrm{Ni}$ and $\mathrm{Al}$ content in the as-coated and thermally cycled state are investigated. For the first time, new small scaled methods are used to obtain fracture toughness and internal stresses of real bond coat systems. Micro cantilever bending and stress relaxation tests were performed on a local scale by employing focused ion beam milling. Additionally, the influence of NiAl composition on Young's modulus and hardness is studied by nanoindentation. Results show an increase of Young's modulus with $\mathrm{Al}$ content. In off-stoichiometric NiAl a higher hardness and fracture toughness than in binary NiAl is found. The internal stresses change from tensile in as-coated to compressive stresses in thermally cycled bond coats, respectively.
\end{abstract}

\section{Introduction}

$\mathrm{NiAl}$ is an attractive intermetallic compound due to its high melting point and high $\mathrm{Al}$ content. Typically, turbine blades in aero engines and stationary gas turbines are coated with bond coats or environmental barrier coatings that are based on $\mathrm{NiAl}$ [1]. Its supreme oxidation resistance makes it the material of choice to protect Ni based superalloys. A drawback is that NiAl is very brittle below the ductile to brittle transition temperature (DBTT). It is in the range of $350^{\circ} \mathrm{C}$ to $600^{\circ} \mathrm{C}[2,3,4]$.

During a regular flight, such a coating has to endure several thermal cycles that traverse this critical temperature. Additionally, mechanical stresses arising from centrifugal forces will also be present at low temperatures which can lead to failure of the brittle coating. Therefore it is necessary to predict how the coating system behaves mechanically at temperatures below the DBTT. A common method for testing mechanical properties is nanoindentation providing local hardness and Young's modulus $[5,6]$. However, these parameters are not sufficient to describe the mechanical behavior of bond coats on turbine blades.

At service temperatures of up to $1100^{\circ} \mathrm{C}$ diffusion and oxidation processes play a major role and the chemical composition changes mainly due to $\mathrm{Al}$ depletion through $\mathrm{Al}_{2} \mathrm{O}_{3}$ formation. Thus a real bond coat is a much more complex system than stoichiometric NiAl. A lot of investigations have been performed on single crystal NiAl and much is known about its mechanical properties and also the temperature and chemical dependence $[7,8,9,10]$. However, real bond coat systems are always off-stoichiometric $\mathrm{NiAl}$ where little data exists particularly with regard to fracture toughness as a function of composition. In most testing approaches bond coats are investigated as an entire entity with or without substrate but not on a grain sized length scale. Therefore a variety of parameters influence the result, which can be eliminated by local analysis. Methods like X-ray diffraction are commonly used to measure residual stresses but due to the diffusion gradient it is not trivial to access the necessary parameters for internal stress determination. In the present work a micro cantilever bending test and a focused ion beam (FIB) milling method with digital image correlation (DIC) are employed to access fracture toughness and internal stresses on a local scale. Here, the samples exhibit a uniform composition and the measurements are independent from the superalloy substrate and other influencing factors. Thus the analyses of the aforementioned properties are simplified.

\section{Experimental}

Material and sample preparation

In this work, the investigated bond coats are CVD processed Al coatings on a Ni-base superalloy (PWA 1484) with corresponding nominal composition listed in Table I.

Table I. Composition of PWA 1484 in weight percent

\begin{tabular}{c|c|c|c|c|c|c|c|c}
$\mathrm{Ni}$ & $\mathrm{Al}$ & $\mathrm{Cr}$ & $\mathrm{Co}$ & $\mathrm{Mo}$ & $\mathrm{W}$ & $\mathrm{Re}$ & $\mathrm{Ta}$ & $\mathrm{Hf}$ \\
\hline Bal. & 5.6 & 4.8 & 10.1 & 1.9 & 5.8 & 2.9 & 8.5 & 0.07
\end{tabular}

The coatings will be designated as $\mathrm{A}$ for the $\mathrm{Al}$ rich sample, $\mathrm{B}$ for the sample with close to stoichiometric NiAl composition and $\mathrm{C}$ for the Ni rich sample. Samples A and B are the as-coated state after a CVD process with different contents of Al. Thermal cycling treatment of a coating A sample was conducted which lead to $\mathrm{Al}$ depletion and $\mathrm{Ni}$ enrichment due to oxidation and diffusion processes in the coating, referred to as sample C. One thermal cycle consists of annealing at $1100{ }^{\circ} \mathrm{C}$ for 24 hours followed by cooling down to room temperature within 30 minutes and subsequent reheating. After 8 cycles an equilibrium state of the system was reached with $\mathrm{Ni}$ enriched NiAl. Additionally, stoichiometric single crystal NiAl was tested in nanoindentation and micro cantilever bending tests as a reference to the bond coat NiAl.

For microstructural analyses the samples were ground followed by polishing steps with diamond suspension with graining from $6 \mu \mathrm{m}$ to $1 \mu \mathrm{m}$. In order to remove most of the remaining mechanical deformation, the samples were polished additionally with $\mathrm{SiO}_{2}$ suspension with a grain size of $0.25 \mu \mathrm{m}$ for 20 minutes.

Energy dispersive X-ray spectroscopy (EDX) and microstructural analyses were performed with a Carl Zeiss Crossbeam Gemini 1540 focused ion beam/scanning electron microscope (FIB/SEM) equipped with a field emission gun. SEM micrographs were recorded in back scattered electron contrast. EDX area scans have a size of $10 \mu \mathrm{m} \times 50 \mu \mathrm{m}$ and were carried out on a cross section of the coating perpendicular to the surface, where the microstructure as well as the composition are homogenous (see Figure 1). The same instrument was also used for H-bar and micro cantilever preparation. Furthermore, phase identification was carried out by X-ray diffractometry using a Siemens D500. Therefore the 
samples were ground and polished parallel to the surface. X-rays with a wavelength of $\lambda=1.5418 \AA\left(\mathrm{Cu}-\mathrm{K}_{\alpha}\right.$ radiation $)$ were detected within a scanning range from $25^{\circ}$ to $85^{\circ} 2 \theta$.

\section{Nanoindentation}

Nanoindentation allows the measurement of local mechanical properties such as Young's modulus and hardness analyzing loaddisplacement curves recorded during controlled loading and unloading with diamond tips. The nanoindentations were carried out on a Nanoindenter XP from MTS with the continuous stiffness module (CSM). Here, the tip is oscillating with a frequency of $45 \mathrm{~Hz}$ allowing to record the contact stiffness over the whole indentation depth as well as a phase- or amplitude shift signal. The data is evaluated by the method presented by Oliver and Pharr [11]. Before and throughout the measurements the tip shape function was determined and no change in radius of the Berkovich indenter was observed.

The indentations were aligned in a grid of $3 \times 15$ indents with a spacing of $15 \mu \mathrm{m}$ to $20 \mu \mathrm{m}$ between each indent and a maximum indentation depth of $500 \mathrm{~nm}$. The plastic zone underneath the indent therefore isn't affected by neighboring indentations. Furthermore, a good resolution and statistic of the measurements is achieved by tilting the indentation field $30^{\circ}$ to $35^{\circ}$ perpendicular to the surface. The indentations reach from the surface over the main coating and inter diffusion zone (IDZ) to the substrate (see Figure 1). Similar experiments have been described in $[6,12]$.

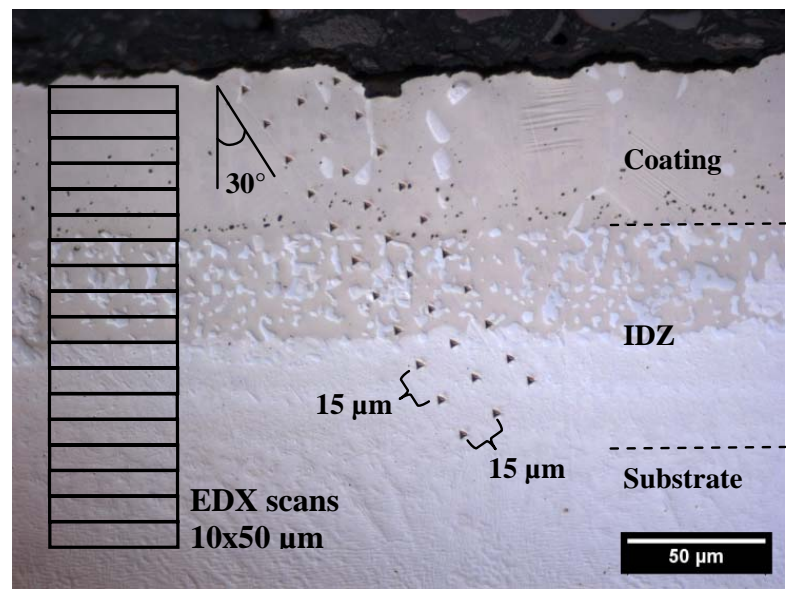

Figure 1. Optical micrograph of an indentation field on sample C. Also displayed are scan areas from the EDX analyses.

Micro cantilever bending tests

The fracture toughness is measured by in-situ bending tests of FIB milled micro cantilevers. Similar experiments have been performed on soft and hard oriented NiAl single crystals where it could be shown that the fracture toughness results compare very well with macroscopic tests [13].

Before milling the samples, the top surface of the bond coat is prepared in order to flatten the surface and to remove an oxide layer to reduce milling time, while cross sections are used to determine the exact location of the micro cantilevers in the bond coat. Therefore, electron backscatter diffraction (EBSD) measurements were carried out to identify grain orientation as well as to create a map of the grain structure. Figure 2 shows a SEM image of sample A with an EBSD map overlay. The map coloring represents the orientation of the grains and the position of the cantilevers is chosen appropriately. Hence, it is possible to mill cantilevers in a single grain. Each $\mathrm{H}$-bar is wide enough to provide enough space to cut two micro cantilevers (notches are indicated as white lines in Figure 2).

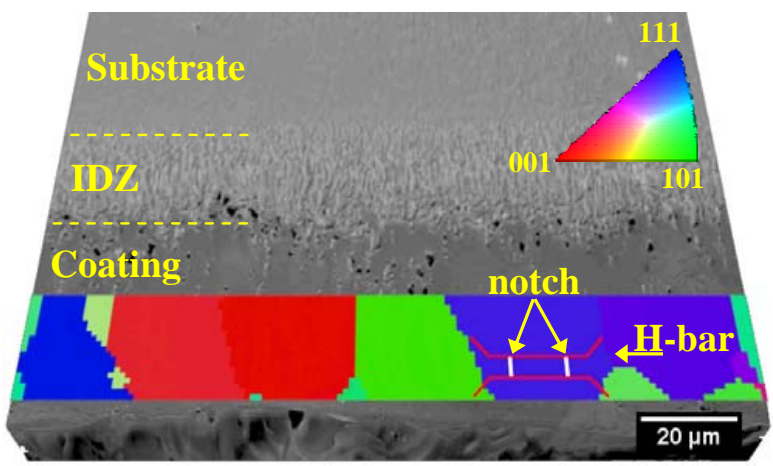

Figure 2. EBSD map overlay of sample A with IPF coloring. The size of an H-bar is displayed in the picture. The notches are indicated with white lines.

Many bending tests on a macroscopic scale have been performed on single crystal $\mathrm{NiAl}[14,15,16]$. It was reported that the grain orientation has an evident influence on fracture toughness. Chang et al [17] have conducted macroscopic bending tests in various orientations on single crystal NiAl. They tested $<110>$ and $<111>$ oriented crystals with a notch direction of $\langle 001\rangle,<-110\rangle$ and $<-112>$ (soft orientation) as well as $<100>$ oriented ones with a notch direction of $\langle 001\rangle$ (hard orientation). The fracture toughness of the soft orientations show no strong difference and are all lower than the hard orientation by a factor of $\approx 2$. Thus it is shown that if the testing setup is not in the hard direction then measured differences in fracture toughness are comparably small. In our experiment no hard orientation was investigated and therefore the assumption can be made that all tested micro cantilevers represent values from a soft direction.

The micro cantilevers are prepared at similar positions from different coatings parallel to the surface to assure consistency in the measurements. In a coarse milling step an H-bar is cut with a high current $\mathrm{Ga}^{+}$-ion beam of $30 \mathrm{kV}$ and consecutive steps of $10 \mathrm{nA}, 2 \mathrm{nA}, 500 \mathrm{pA}$ at the desired position. With a fine milling step employing lower currents of $50 \mathrm{pA}$ to $200 \mathrm{pA}$ and $30 \mathrm{kV} \mathrm{a}$ cantilever (cf. Figure 4) is formed with approximate dimensions of $8 \mu \mathrm{m}$ length, a width $w$ of $2 \mu \mathrm{m}$ and a thickness $B$ of $1.8 \mu \mathrm{m}$. Afterwards, a notch is milled from the top of the cantilever with a finer current of $5 \mathrm{pA}, 30 \mathrm{kV}$ until a depth to width ratio $a / w$ of 0.15 to 0.30 is achieved. In a further milling step the H-bar is split in the middle into two cantilevers. An overview of finished micro cantilevers on a bond coat (sample C) is shown in Figure 3. They are cut in a homogenous part of the coating. The former H-bars are named $\mathrm{C} 1$ to $\mathrm{C} 3$. Each $\mathrm{H}$-bar was divided into two cantilevers $\mathrm{a}$ and $\mathrm{b}$. The crosses between the micro cantilevers are markers used for drift correction during the milling process by the FIB microscope. The description of the coating's microstructure will be given later.

Important for determining the fracture toughness of a single grained micro cantilever is that the notch is not on a grain boundary. The crack will only be exposed to the local crystallographic orientation and subsequent glide systems and cleavage planes. Since the cantilevers are smaller than the average grain size, it is possible to determine fracture toughness of an individual grain. The notches are always cut inside such a grain. 
This also means that the results can be compared with values from single crystals.

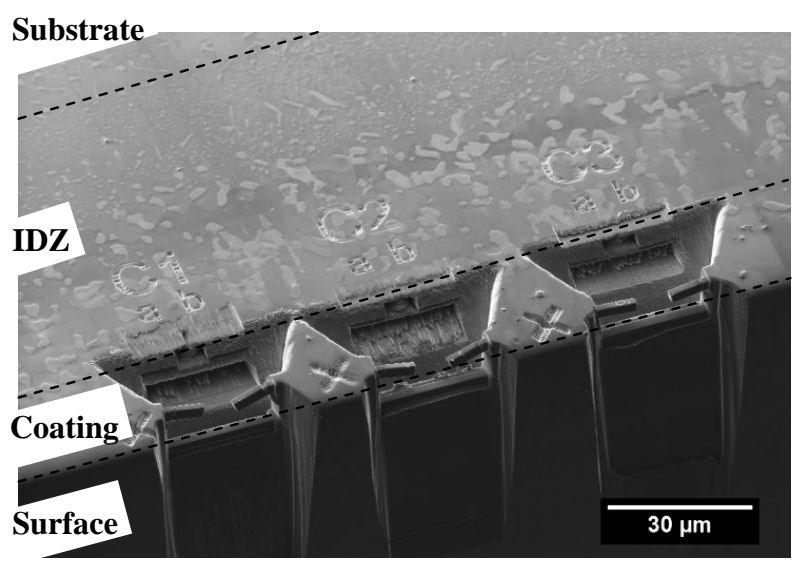

Figure 3. Overview of tested micro cantilevers on sample C.

A force measurement system (FMS), from Kleindiek Nanotechnik, Germany, is used for loading of the micro cantilevers. Three dimensional movements of the indenter are possible through a micromanipulator built in the FMS. The indenter is a $110 \mu \mathrm{m}$ long AFM cantilever which is coated with a piezoresistive film generating a voltage signal upon bending. It is converted into a force signal with a resolution of around $1 \mu \mathrm{N}$.

At the beginning of the in-situ bending test the indenter tip is placed in the middle of the cantilever in a distance of about $6 \mu \mathrm{m}$ from the notch (see Figure 4). During the test it is essential to make sure that the indenter tip stays at this location. The micro cantilevers were loaded manually as the FMS system does not offer a software control for predefining the loading rates. Strain rate controlled experiments are therefore not possible.

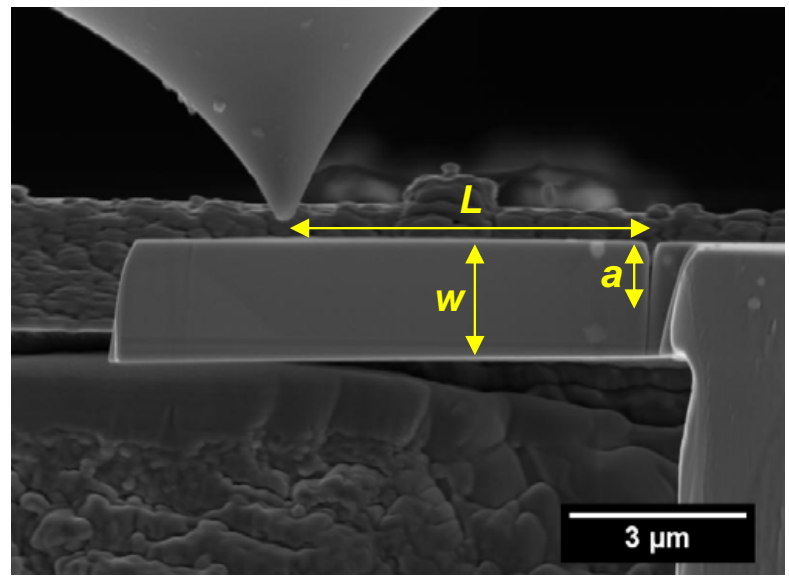

Figure 4. SEM image of the side view of the indenting tip and micro cantilever.

Great care was taken to apply the same loading rate during experiments. Finally, the cantilevers were loaded until fracture and the exact dimensions of the micro cantilevers were measured. The fracture toughness is evaluated at the maximum load according to equation:
$K_{I c}=\frac{F_{\max } L}{B w^{\frac{3}{2}}} f\left(\frac{a}{w}\right)$

where $F_{\max }$ is the maximum load on the cantilever and $L$ the distance between the notch and the loading position. The dimensionless geometry factor $f$ describes the used cantilever geometry.

\section{$\underline{\text { Residual stress measurement }}$}

In general, by removing material the equilibrium of internal stresses is disturbed which leads to a displacement of the surrounding material. However, instead of macroscopic hole drilling an H-bar is milled on the microscopic scale by employing a FIB. Before milling, the samples with coatings $\mathrm{A}$ and $\mathrm{C}$ were prepared as already described for the bending tests. Additionally, in order to reduce the deformation zone chemo-mechanical polishing or electrolytic polishing was performed.

Afterwards, markers are milled next to the testing site with the FIB and the initial state is recorded by high resolution SEM imaging.

Employing a multi-step FIB milling process with drift correction an H-bar is created (see Figure 5) and the milled site is recorded again. Due to the removal of material in the vicinity of the bar internal stresses can relax and cause immediate thickening or thinning. The displacement gradient was determined by comparing high resolution SEM images before and after milling with DIC. A subpixel algorithm was used to improve the accuracy of the correlation.

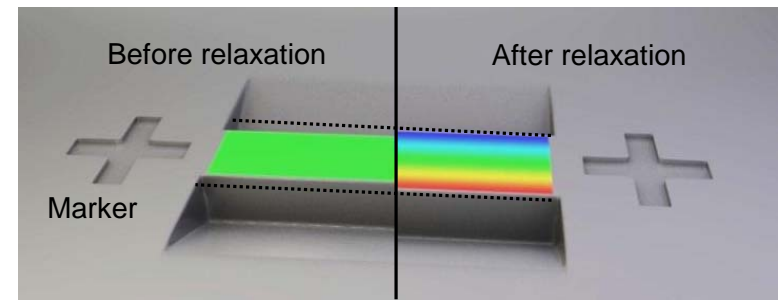

Figure 5. Visual display of the displacement gradient on a relaxed FIB milled H-bar.

Displacements along the width of the bar are extracted and plotted along their position. From this plot the average strain is obtained by linear regression. Furthermore, on all bars EBSD measurements are performed to determine the crystallographic orientation of the examined grain. In order to calculate residual stresses Hooke's law is used. The measured strain is multiplied with an elastic modulus specific for the crystallographic orientation.

Cuts were made on the cross section of the samples. The testing sites are positioned approximately $10 \mu \mathrm{m}$ next to the coating surface but the relaxing areas are oriented perpendicularly to the cross section and sample surface. Since neither the sample surface nor the cross section can bear stresses the only direction containing stresses is parallel to the cross section. Thus the bar is oriented in stress direction (see Figure 6). The milling position is chosen so that the H-bar consists of a single grain only. 


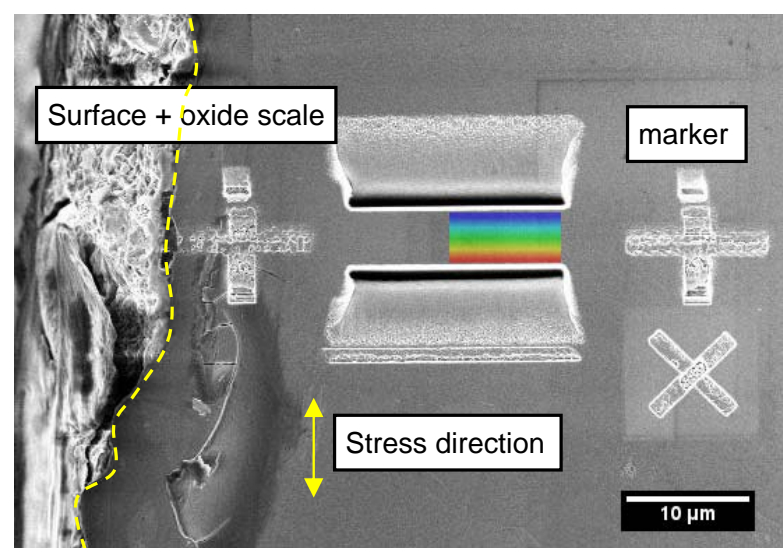

Figure 6. Cross section of sample $\mathrm{C}$ of a testing site after milling with orientation markers and displacement gradient.

\section{Results}

\section{XRD Analysis}

Figure 7 shows the X-ray spectra of all three coatings. They reveal that in all coatings $\beta$-NiAl with a body centered cubic intermetallic B2 structure is present. Coating $\mathrm{C}$ however, has a second phase which is face centered cubic $\gamma^{\prime}-\mathrm{Ni}_{3} \mathrm{Al}$ with $\mathrm{L1}_{2}$ structure. It arises from $\mathrm{Al}$ depletion as a result of in- and outward diffusion of $\mathrm{Al}$ along the grain boundaries, which is the preferred diffusion path. $\mathrm{Al}$ forms a dense $\mathrm{Al}_{2} \mathrm{O}_{3}$ layer on top of the coating and also diffuses towards the substrate because of the chemical gradient (see Figure 10). Formation of $\gamma^{\prime}-\mathrm{Ni}_{3} \mathrm{Al}$ occurs at temperatures of $1100{ }^{\circ} \mathrm{C}$ during thermal cycling.

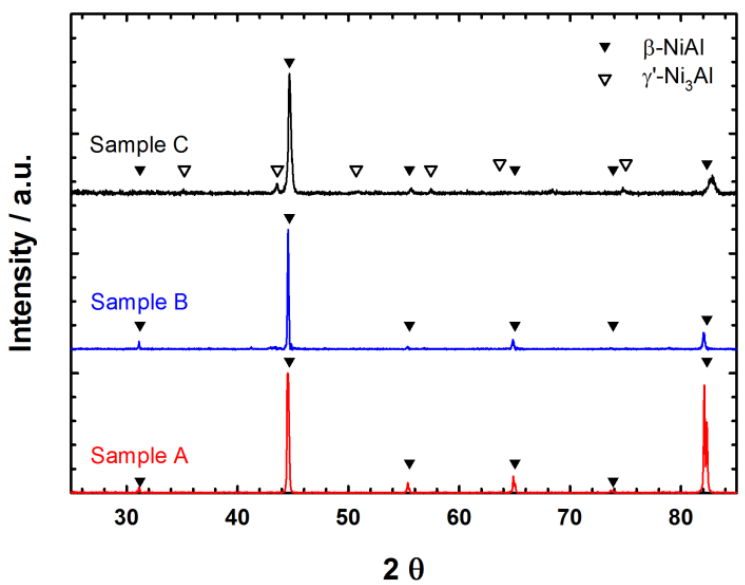

Figure 7. XRD scans of samples A, B and C. Filled triangles represent $\mathrm{NiAl}$ and empty triangles $\mathrm{Ni}_{3} \mathrm{Al}$ peak positions in $2 \theta$ values.
The diffraction peaks from the NiAl phase in the thermally cycled sample $\mathrm{C}$ are shifted to higher $2 \theta$ values compared to diffraction angles $2 \theta$ of stoichiometric NiAl because of the change in the lattice parameter due to the high $\mathrm{Ni}$ and Co fraction. This can be explained by the fact that off-stoichiometric $\mathrm{NiAl}$ with high $\mathrm{Ni}$ content has a lower lattice parameter $(2.864 \AA)$ than binary NiAl $(2.887 \AA)[18]$.

Microstructure and chemical composition

The microstructure of the investigated samples is shown in Figure 8 to Figure 10 with the corresponding composition from EDX analysis in Figure 11 to Figure 13. The main elements like $\mathrm{Al}, \mathrm{Ni}, \mathrm{Cr}$ and $\mathrm{Co}$ are shown separately while the accumulated concentration of the refractory elements like Mo, W, Ta, Re and $\mathrm{Hf}$ is displayed as filled squares. The average composition of the samples is summarized in Table II.

Since the coatings are applied with a CVD process followed by diffusion annealing at high temperatures an inter diffusion zone (IDZ) with a large volume fraction of intermetallic precipitates has developed between the bond coat and the substrate of each sample. These precipitates are rich in $\mathrm{Cr}, \mathrm{Mo}, \mathrm{Ta}, \mathrm{W}$ and Re. In the as-coated state both samples A and B have a sharp interface between IDZ and substrate (see Figure 8 and Figure 9).

Coating A exhibits a mostly homogenous microstructure with a grain size of approximately $20 \mu \mathrm{m}$, consisting of $\beta$-NiAl grains.

Only at grain boundaries very small precipitates are observed. The chemical composition of coating A is relatively constant (see Figure 11 and Table II).

Coating $\mathrm{B}$ has an inhomogeneous microstructure with precipitates equally distributed throughout most of the coating. A slight accumulation of precipitates is found close to the surface and above the IDZ. EDX analyses show a corresponding enrichment of $\mathrm{Cr}$, which is also constantly higher than the Co fraction. The Al content is equal to Ni close to the IDZ and increases towards the surface, where its fraction is slightly higher than $\mathrm{Ni}$.

The microstructure of coating $\mathrm{C}$ consists of a broad homogenous region underneath the surface with a second phase at the grain boundaries and a large volume fraction of precipitates in the IDZ. There, two types of precipitates are found. The bright phases contain $\mathrm{Cr}, \mathrm{W}, \mathrm{Mo}, \mathrm{Re}$ and the light grey phases are identified as $\gamma^{\prime}-\mathrm{Ni}_{3} \mathrm{Al}$. The surrounding matrix is $\beta$-NiAl. Close to the substrate the bond coat is enriched in $\mathrm{Al}$ and mainly $\gamma^{\prime}$ is observed. Additionally also small $\mathrm{W}$ and $\mathrm{Re}$ rich precipitates are found, which change in appearance closer to the substrate and become needle-shaped. In literature [19], theses phases are reported to be topologically closed packed $\sigma$-phases. Coating $\mathrm{C}$ has the highest $\mathrm{Ni}$ fraction (54 at- $\%$ ) of all the bond coats investigated. The concentration of $\mathrm{Co}+\mathrm{Ni}$ is 62.3 at. $-\%$ (see Table II) which is close to the phase boundary of $\beta+\gamma$ ' but still in the $\beta$-NiAl phase field. Keeping in mind that this sample was heat treated at $1100{ }^{\circ} \mathrm{C}$ followed by rapid cooling to room temperature so that no other phases than $\beta-\mathrm{NiAl}$ and $\gamma^{\prime}-\mathrm{Ni}_{3} \mathrm{Al}$ have formed. Accordingly the coating consists of these two phases with an equal chemical distribution from 20 to $60 \mu \mathrm{m}$ below the surface.

Table II. Coating composition in atomic percent.

\begin{tabular}{lccccc}
\hline \multicolumn{1}{c}{ Sample } & $\mathrm{Ni}$ & $\mathrm{Al}$ & $\mathrm{Cr}$ & $\mathrm{Co}$ & Refractory elements \\
\hline A (as-coated) & $36.0 \pm 1.5$ & $52.9 \pm 2.6$ & $3.6 \pm 0.2$ & $6.3 \pm 0.3$ & $1.3 \pm 0.5$ \\
B (as-coated) & $43.3 \pm 1.7$ & $45.1 \pm 2.2$ & $5.3 \pm 2.2$ & $5.4 \pm 0.3$ & $0.9 \pm 0.6$ \\
C (A-8 cycles) & $53.4 \pm 1.1$ & $30.6 \pm 2.2$ & $6.2 \pm 0.2$ & $7.8 \pm 0.2$ & $2.1 \pm 0.7$ \\
\hline
\end{tabular}


The increasing $\mathrm{Al}$ content and dropping Ni content right beneath the surface is due to the formation of aluminum oxide. Scans for oxygen are omitted in Figure 13 because oxygen was only detected in the oxide layer and not in the coating. A low influence

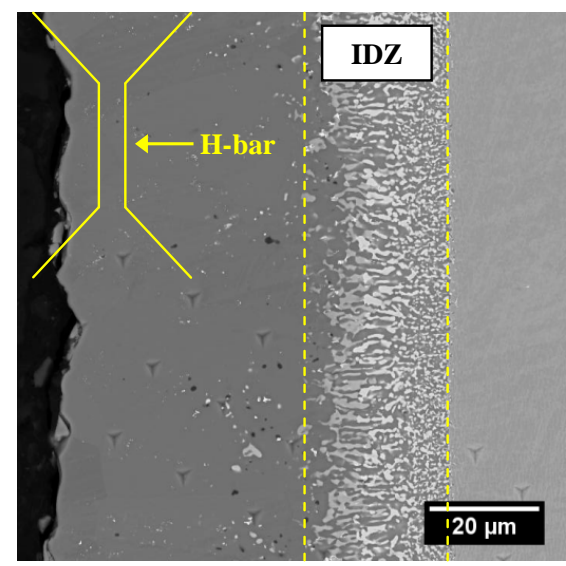

Figure 8. SEM micrograph of sample A.

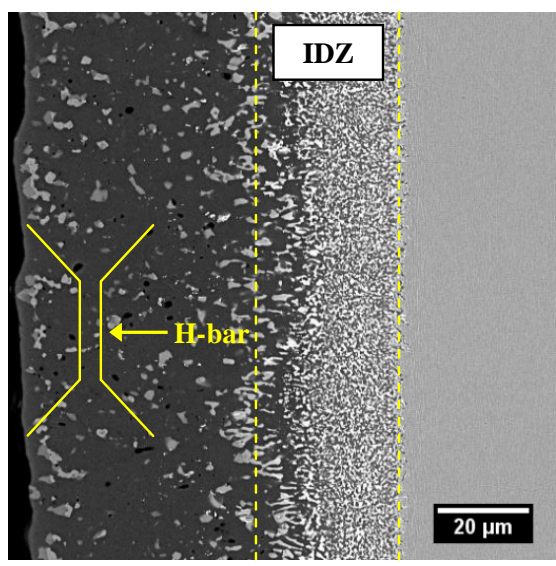

Figure 9. SEM micrograph of sample B.

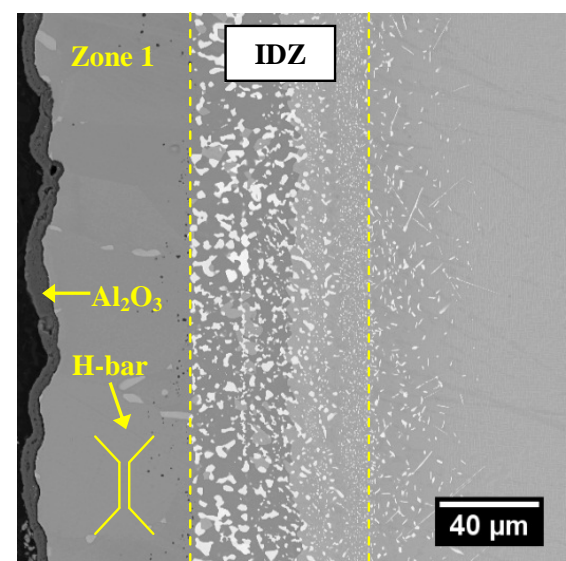

Figure 10. SEM micrograph of sample C. of the refractory elements is expected since their combined fraction is approximately 2 at.- $\%$ or less in the area where the micro cantilevers are located.

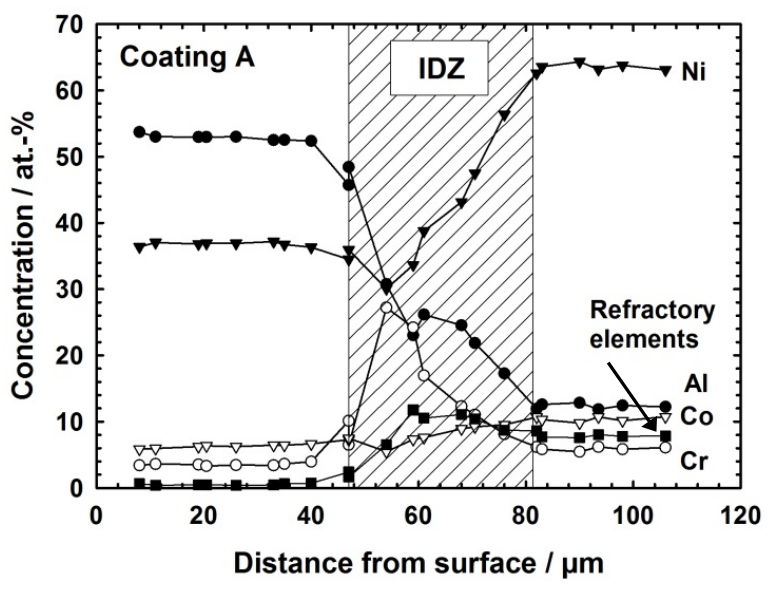

Figure 11. EDX scan of sample A.

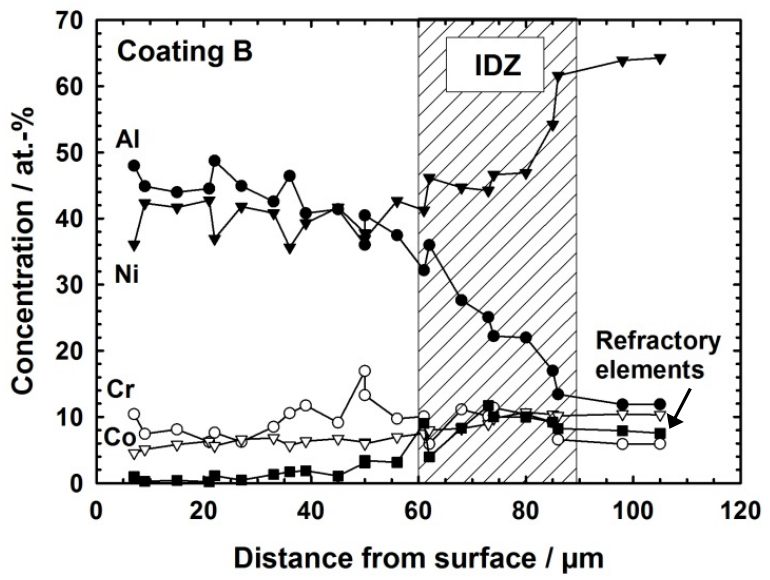

Figure 12. EDX scan of sample B.

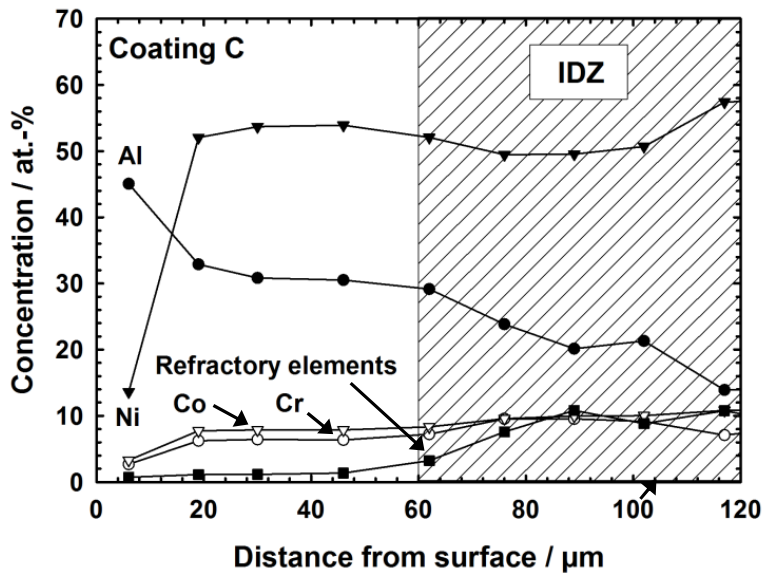

Figure 13. EDX scan of sample C. 


\section{Nanoindentation}

The Young's modulus and hardness obtained from nanoindentation are shown in Figure 14 and Figure 15. The mechanical properties follow the same trend as the chemical composition. The highest Young's modulus of $(225 \pm 10) \mathrm{GPa}$ and hardness values of $10.5 \mathrm{GPa}$ are found for the $\mathrm{Al}$ rich $\beta-\mathrm{NiAl}$ in sample A. For a lower $\mathrm{Al}$ content in $\beta$-NiAl in sample $\mathrm{B}$ and $\mathrm{C}$, the hardness drops to $8 \mathrm{GPa}$ and $6 \mathrm{GPa}$ respectively. For sample $\mathrm{C}$, the Young's modulus has also the lowest value of $125 \mathrm{GPa}$. A large scattering is observed in the IDZ, especially for sample $\mathrm{C}$, due to the indentation of hard intermetallic particles in a much softer matrix.

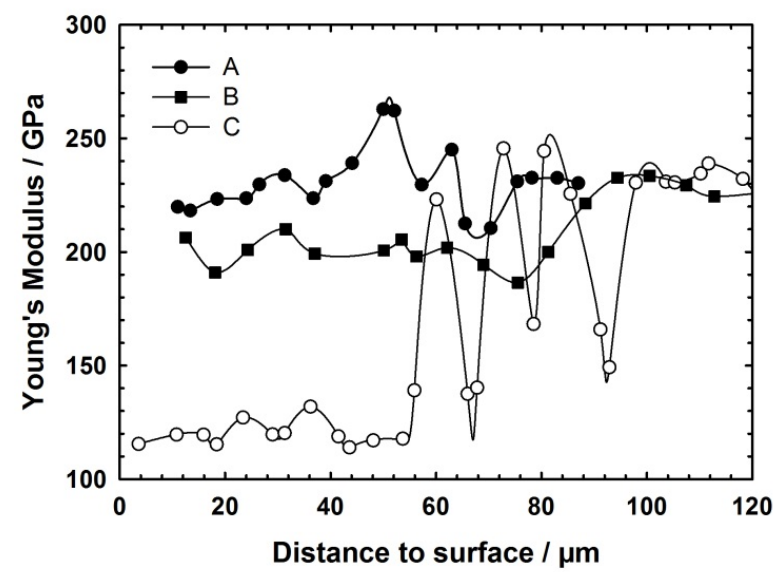

Figure 14. Young's modulus profile of tested samples.

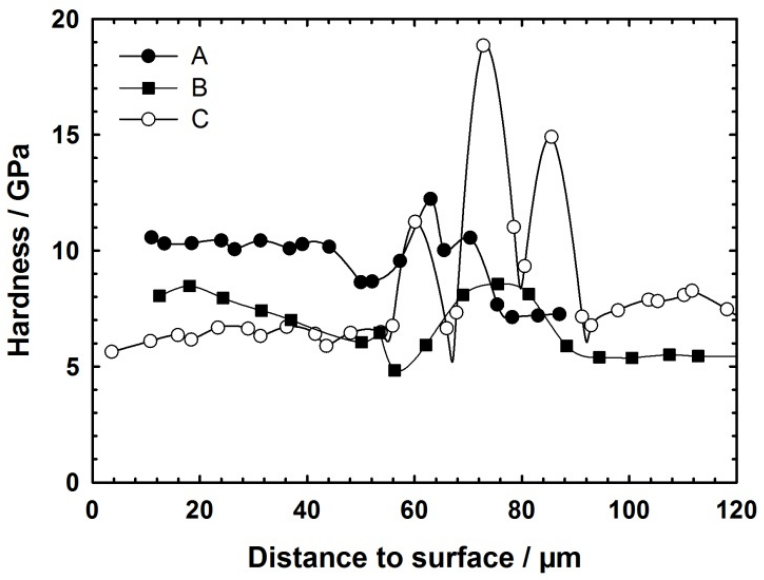

Figure 15. Hardness profile of tested samples.

\section{Micro cantilever bending tests}

The micro cantilevers were milled in the homogenous regions of the different coatings (see yellow markings in Figure 8 to Figure 10). During loading, the cantilevers deform mainly elastically. However, in the vicinity of the crack tip a plastic zone is formed as it is described by Iqbal et al [13]. As the loading force increases the crack opens which is followed by immediate catastrophic failure. Figure 16 shows the $K_{I C}$ values obtained from the micro cantilever experiments over the combined $\mathrm{Al}+\mathrm{Cr}$ content. This is reasonable since $\mathrm{Cr}$ partitions mostly to Al lattice sites $[20,21]$. Co on the other hand favors only Ni sites and can be added to the Ni content raising it to 43 at.- $\%[22,23]$.
Stoichiometric NiAl has the lowest fracture toughness of all tested compositions $\left(1.43 \mathrm{MPa} \cdot \mathrm{m}^{1 / 2}\right)$. The deviation from stoichiometry results in an increase of $K_{I C}$ for both $\mathrm{Al}$ rich (sample $\mathrm{A}$ ) and $\mathrm{Ni}$ rich (sample C) regions of the phase field. Sample B differs only slightly but shows already a higher value of $1.76 \mathrm{MPa} \cdot \mathrm{m}^{1 / 2}$. An even higher $\mathrm{Al}+\mathrm{Cr}$ fraction leads to a moderate gain of fracture toughness. However, the Ni rich sample $\mathrm{C}$ has the highest value of all tests $\left(2.77 \mathrm{MPa} \cdot \mathrm{m}^{1 / 2}\right)$ which is almost two times of the stoichiometric NiAl.

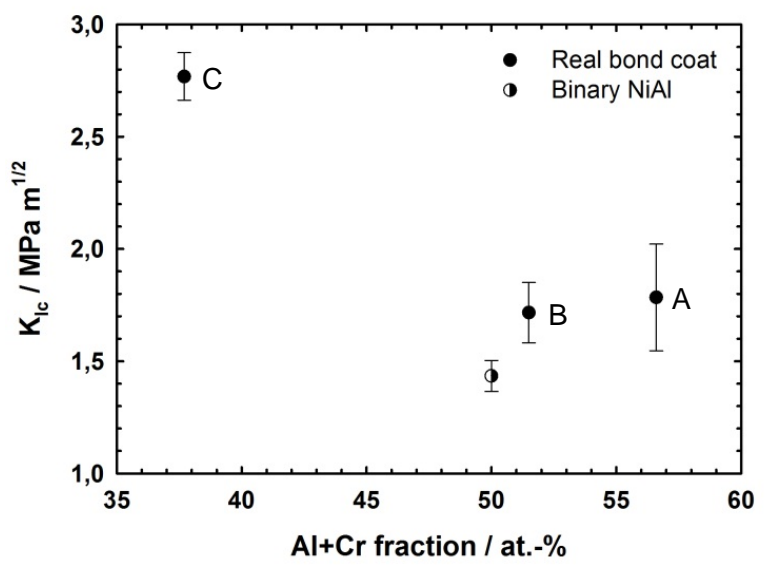

Figure 16. Fracture toughness vs. combined $\mathrm{Al}+\mathrm{Cr}$ concentration of all tested micro cantilevers (filled symbols) and stoichiometric binary $\mathrm{NiAl}$ (semi-filled symbols).

The fracture surface of a micro cantilever from the $\mathrm{Ni}$ rich sample $\mathrm{C}$ is shown in Figure 17. A fissured fracture surface is found, which appearance is representative for all tested micro cantilevers of sample C. The crack is deflected into specific cleavage planes of the crystal. In comparison, sample B typically has a smooth and flat fracture surface (see Figure 18), indicating an entirely brittle fracture.

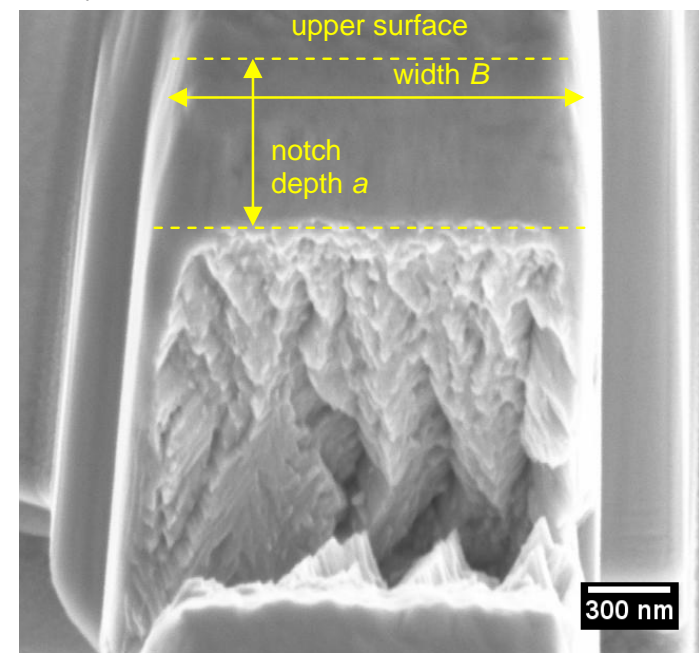

Figure 17. SEM micrograph showing a representative fracture surface of a sample $\mathrm{C}$ ( $\mathrm{Ni}$ rich $\mathrm{NiAl}$ ) coating. The initial notch depth $a$ is measured after the fracture as well as the exact width $B$ of the micro cantilever. 


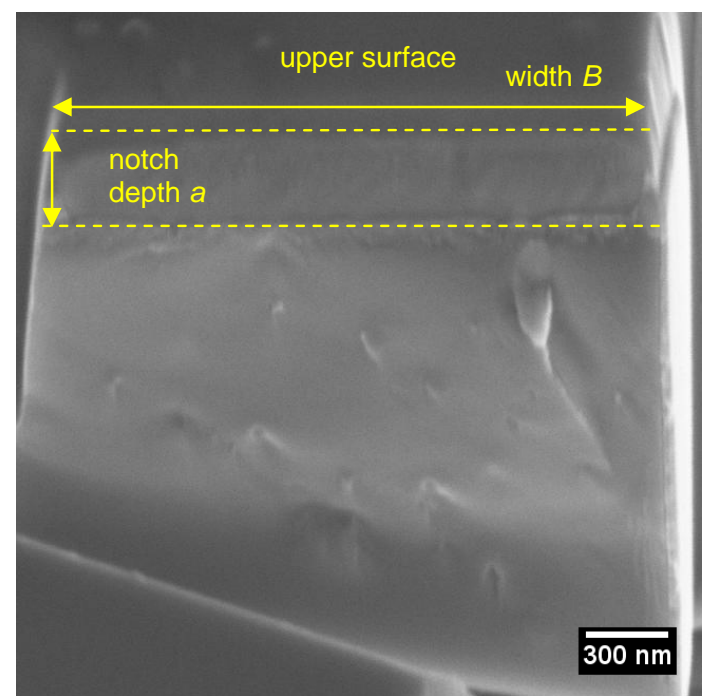

Figure 18. SEM micrograph showing a representative fracture surface of a sample $\mathrm{B}(\mathrm{c}(\mathrm{Al}) \approx \mathrm{c}(\mathrm{Ni}) \mathrm{NiAl})$ coating.

Residual stress measurements

Figure 19 shows a milled H-bar with the displacement field extracted from DIC. The displacements are extracted from the center of the bar and are plotted in Figure 20 as a function of the coordinates on the H-bar together with a linear regression, where the slope represents the average strain due to stress relaxation.

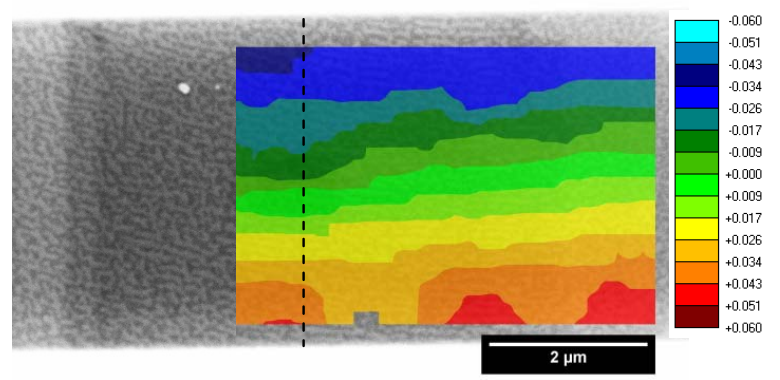

Figure 19. Micrograph of sample A after milling with superposed displacement gradient (in $\mathrm{nm}$ ) and dashed line of data extraction.

Elastic anisotropy of NiAl ranges from 3.2 to over 30 [24]. Therefore, the grain orientation is important for the calculation of stresses from the relaxation strains, for which Hooke's law is used. The orientation data is extracted from EBSD maps in form of Bunge Euler angles.

To estimate the elastic behavior the Young's modulus $E$ in the relaxation direction is calculated using equation (2) [25].

$$
\mathrm{E}\left(\varphi_{1}, \Phi, \varphi_{2}\right)=\left(S_{11}-2\left[\left(S_{11}-S_{12}\right)-0.5 S_{44}\right]\left(l^{2} m^{2}+m^{2} n^{2}+l^{2} n^{2}\right)\right)^{-1}
$$

$S_{i j}$ represents coefficients of the stiffness matrix. The grain rotation is given by the Bunge Euler angles $\left(\varphi_{1}, \Phi, \varphi_{2}\right)$ and the direction cosines $l, m$ and $n$ are expressed in following equations (for explanation see appendix):

$$
\begin{aligned}
& l=\sin \varphi_{1} \cos \varphi_{2}+\cos \varphi_{1} \sin \varphi_{2} \cos \Phi \\
& m=-\sin \varphi_{1} \sin \varphi_{2}+\cos \varphi_{1} \cos \varphi_{2} \cos \Phi \\
& n=-\cos \varphi_{1} \sin \Phi
\end{aligned}
$$

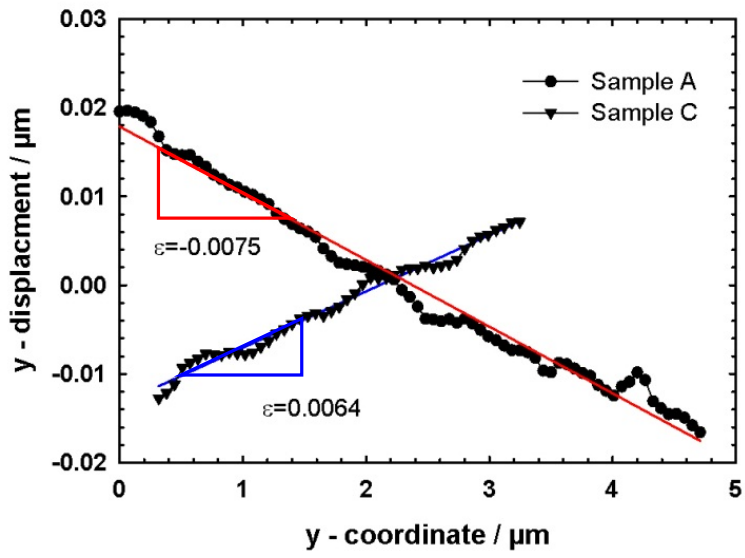

Figure 20. Displacement plot of sample A and C with linear fit for determination of average relaxation strain.

The elastic constants are taken from literature [24, 26], using the combined $\mathrm{Ni}+\mathrm{Co}$ concentration as an equivalent $\mathrm{Ni}$ content (See Table III)

Table III. Used parameters for elastic modulus calculation.

\begin{tabular}{cccc}
\hline Sample & $\begin{array}{c}\mathrm{Ni}+\mathrm{Co} \\
/ \text { at } \%\end{array}$ & $\begin{array}{c}C_{11} ; C_{12} ; C_{44} \\
/ \mathrm{GPa}\end{array}$ & $\begin{array}{c}\text { Orientation } \\
\left(\varphi_{1}, \Phi, \varphi_{2}\right)\end{array}$ \\
\hline $\mathrm{A}$ & 45 & $213 ; 110 ; 94^{[} 24^{]}$ & $(132 ; 33 ; 19)$ \\
$\mathrm{C}$ & 62.5 & $168 ; 159 ; 120^{\left[26^{]}\right.}$ & $(243 ; 44 ; 53)$ \\
\hline
\end{tabular}

The elastic anisotropy and grain orientation of the individual grains are displayed in Figure 21. The corresponding elastic moduli and stresses are presented in Table IV.
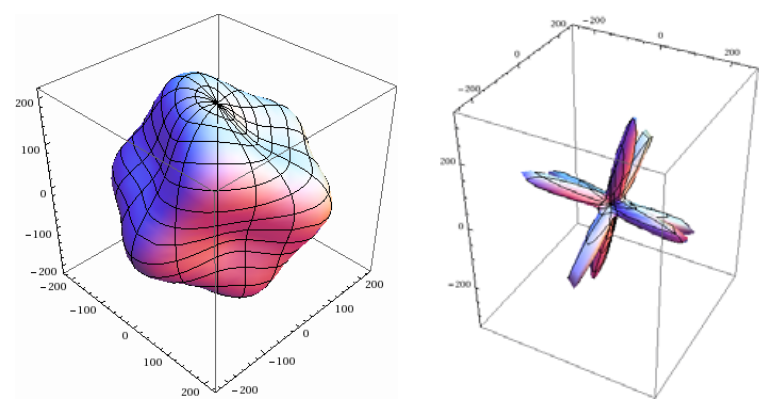

Figure 21. Graphical representation of elastic anisotropy of sample A (left) and C (right) in measured orientation.

Table IV. Results of residual stress measurement (positive: tensile stress, negative: compressive stress).

\begin{tabular}{cccc}
\hline Sample & $\mathrm{E}_{(h k l)} / \mathrm{GPa}$ & Strain / \% & Stress / GPa \\
\hline $\mathrm{A}$ & 207 & -0.75 & 1.55 \\
$\mathrm{C}$ & 51 & 0.64 & -0.33 \\
\hline
\end{tabular}

Relaxation strain was found in the as-coated sample A of $-0.75 \%$ (compressive) and after cycling (sample C) of $0.64 \%$ (tensile). Applying Hooke's law tensile stresses of $1.55 \mathrm{GPa}$ and $-0.33 \mathrm{GPa}$ are obtained, respectively. Due to the nature of this experiment a negative relaxation strain corresponds to positive internal strain 
and stress. Considering the bar being in tension it contracts on relaxation which is measured as compressive strain and vice versa.

\section{Discussion}

The results show that changes in chemical composition lead to different mechanical properties of the coating regarding hardness, Young's modulus and fracture toughness. Furthermore, thermal cycling of bond coats leads to changes of internal stresses.

\section{Hardness and Young's modulus}

The hardness measurements for stoichiometric single crystal NiAl are in good agreement with Pike et al. [18] (see Figure 22), who conducted micro hardness tests using a Vickers diamond indenter and converted the Vickers hardness to load over projected area. This proves that hardness from nanoindentation is comparable to different test setups. In off-stoichiometric NiAl the hardness increases to the $\mathrm{Ni}$ rich as well as to the $\mathrm{Al}$ rich side of the phase field which is consistent to the results published by Pike et al. This is attributed to anti-site $\mathrm{Ni}$ atoms for $\mathrm{Ni}$ rich $\mathrm{NiAl}$ and to vacancies for the $\mathrm{Al}$ rich case [27]. It is known that the hardening effect of vacancies is stronger than of Ni anti-sites [28]. Therefore the hardness of the Al rich samples A and B is higher than the stoichiometric $\mathrm{NiAl}$ and the $\mathrm{Ni}$ rich sample $\mathrm{C}$. The generally higher hardness values of the bond coats in comparison to Pike's results are probably due to solved $\mathrm{Cr}$ and $\mathrm{Co}$ atoms. $\mathrm{Cr}$ is a potential solid solution hardener [22]. Also micro alloying of refractory elements from the substrate could be a reason for higher hardness [7].

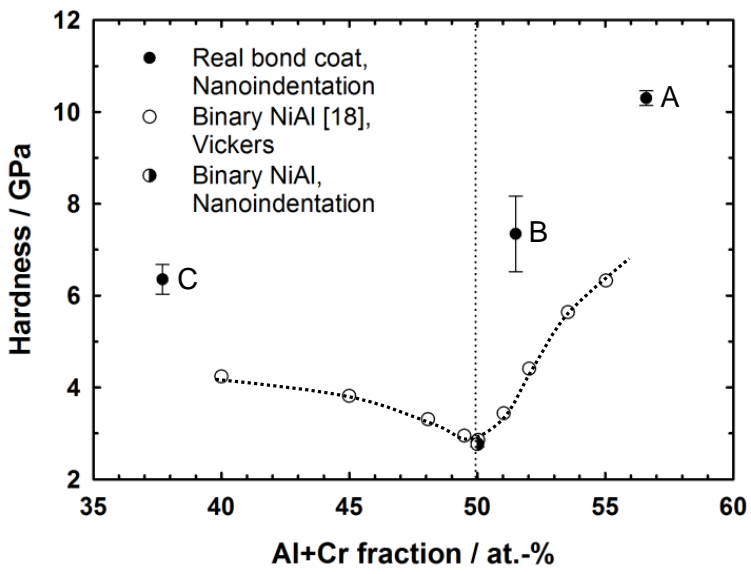

Figure 22. Hardness vs. combined $\mathrm{Al}+\mathrm{Cr}$ content from nanoindentation is displayed as filled circles and micro hardness by Vickers indentation [18] as empty circles. The semi-filled circle represents binary $\mathrm{NiAl}$ also tested by nanoindentation.

The Young's moduli of the different coatings, derived by nanoindentation, agree well with results from Rusovic et al [29] on bulk single crystal NiAl. The Ni rich sample has a much lower Young's modulus than stoichiometric NiAl as well as the $\mathrm{Al}$ rich samples. In the $\mathrm{Ni}$ rich case, there are more $\mathrm{Ni}-\mathrm{Ni}$ bonds in the crystal compared to binary $\mathrm{NiAl}$ and $\mathrm{Al}$ rich NiAl. These bonds have a more metallic character than $\mathrm{Ni}-\mathrm{Al}$ bonds which are assumed to be of more ionic type. However, the Young's modulus is also controlled by the binding energy of atomic bonds, which is related to the enthalpy of formation. Nash et al. [30] determined the enthalpy of formation for NiAl compounds with a mole fraction in the range of $0.44 \mathrm{Ni}$ and $0.62 \mathrm{Ni}$.

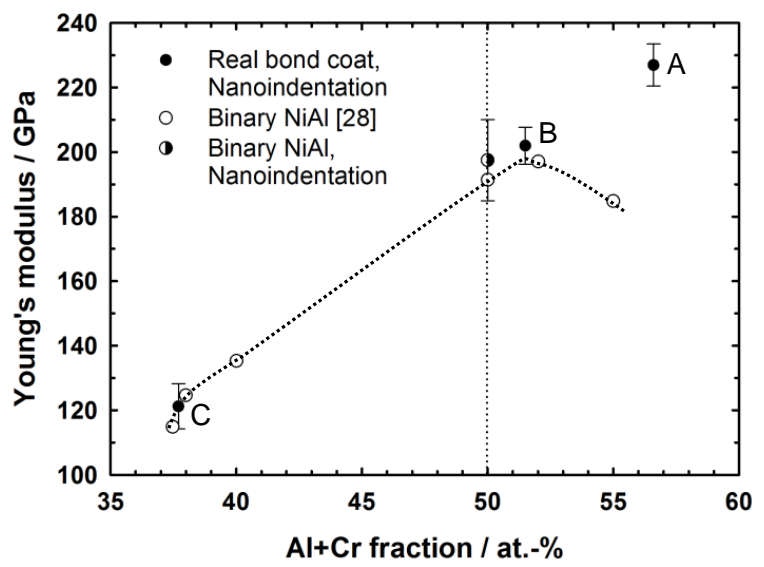

Figure 23. Young's modulus vs. $\mathrm{Al}+\mathrm{Cr}$ content. Filled (bond coat) and semi-filled (binary NiAl) symbols show results from nanoindentation. Empty circles represent data from Rusovic [29].

The most negative values are at stoichiometric NiAl and hence this is the most stable composition. They observed a continuous increase for both $\mathrm{Ni}$ and $\mathrm{Al}$ rich NiAl. Accordingly, the Young's modulus should have its maximum at stoichiometric composition. However, our data reveal the highest values for the Al rich sample. This could be attributed to the solved Co. Since Co substitutes Ni some bonds will be $\mathrm{Co}-\mathrm{Al}$ which are even stronger than Ni-Al bonds. The Young's modulus of CoAl which is $295 \mathrm{GPa}$ [31] reflects stronger bonding. Therefore a higher Co to $\mathrm{Ni}$ ratio in sample A compared to sample B might lead to a higher fraction of Co-Al bonds which could cause the higher Young's modulus of sample A.

Micro cantilever bending tests

After FIB milling of the micro cantilevers, the precedent residual stresses will relax and therefore they are stress free. However, many factors contribute to the fracture toughness of a material. The bonding strength and the type of bonds between atoms have to be considered. Additionally, potential dislocation movement has to be taken into account. This is also correlated with crystal orientation and which glide system may be activated or rather the number of glide systems. In single crystalline pure NiAl or other materials the crystal orientation influences the mechanical behavior in a major way. In the presented results (see Figure 16), it is assumed that only soft orientations of $\mathrm{NiAl}$ are tested i.e. that dislocation movement is only possible on $<100\rangle$ glide planes and that cleavage fracture will occur on $\langle 110\rangle$ planes. The error bars indicate no large scatter and therefore confirms that no hard orientation was among the tested cantilevers. This means, that the influence of composition could be probed with these tests. The fracture toughness shows a similar behavior like hardness as a function of $\mathrm{Al}$ fraction. $K_{\mathrm{IC}}$ is increasing with the $\mathrm{Ni}$ and $\mathrm{Al}$ content, respectively. The reduced hardness of the Ni rich sample does agree with the fact that it has the highest fracture toughness measured. The difference in fracture toughness is not very large but the fracture surfaces show major differences between high and low Al content. The SEM images suggest that plasticity might have occurred in the Ni rich NiAl, which could be the reason for its higher fracture toughness compared to $\mathrm{Al}$ rich NiAl. Yet a contradiction is found compared to literature where the fracture 
toughness of single crystal NiAl containing 46 at.- $\% \mathrm{Al}$ is even lower than of stoichiometric NiAl [17]. Our results reveal the opposite. A deviation from stoichiometry leads to a higher fracture toughness, especially in the low Al regime. In this case, $\mathrm{Ni}$ will substitute on $\mathrm{Al}$ sites and therefore more $\mathrm{Ni}-\mathrm{Ni}$ bonds will be present. Their bond character is more metallic and hence more ductile than Ni-Al bonds. Additionally in the high Al regime, $\mathrm{Ni}$ atoms are replaced with vacancies. Therefore the number of $\mathrm{Ni}-\mathrm{Al}$ bonds is also reduced and as a result fracture toughness should be raised and could explain the observed trend.

The $K_{I C}$ values are generally lower than in literature $[13,17,15$, 32], where NiAl in soft direction has $3 \mathrm{MPa} \cdot \mathrm{m}^{1 / 2}$ to $5 \mathrm{MPa} \cdot \mathrm{m}^{1 / 2}$. However, it seems that alloying additions like $\mathrm{Cr}$, $\mathrm{Co}$ and refractory elements also have an influence on fracture toughness. Size effects from the different length scale of the micro cantilever bending tests could also contribute to lowering fracture toughness compared to data from macroscopic experiments. Various crystallographic orientations of the cantilevers could be another reason for this deviation. Further investigations are necessary to explain the divergence from literature values.

\section{$\underline{\text { Residual stress measurements }}$}

By recording the relaxation strain it is possible to estimate the internal stresses at a local length scale. Due to the milling geometry only relaxation in one certain direction is possible and thus only residual stresses acting in this orientation can be measured. The uniaxial Hooke's law can thus be used and offers a good approximation for calculation of stresses. Further, the proposed method provides microstresses which change over a length scale of a few grains and can therefore contain stresses caused by the microstructure of the material system e.g. precipipates or intergranular mismatch.

The wafer curvature method was used by Watanabe et al. to determine residual stresses of bond coats itself. They obtained tensile stresses of $140 \mathrm{MPa}$ for a PtNiAl system [33]. The measurement is consistent with stresses produced by thermal expansion coefficient (CTE) mismatch $\Delta \alpha$ of the coating system. Strain and stress are calculated with $\Delta \alpha$ of $+1.5 \cdot 10^{-6} /{ }^{\circ} \mathrm{C}$ and $\Delta \mathrm{T}$ of $700{ }^{\circ} \mathrm{C}$ (see eq. 6). Comparing Watanabe's result to the here measured $1.55 \mathrm{GPa}$ a substantial difference can be observed. This deviation results from the fact that in Watanabe's work only the CTE mismatch is considered. However in complex systems like bond coats more mechanisms influencing residual stresses can be found.

Balint and Hutchinson proposed a model to describe a process referred to as rumpling which is caused by internal stresses. This is observed as a sinusoidal deformation of the bond coat/oxide interface upon thermal cycling. Among many parameters stress evolution during temperature change is calculated on PtNiAl bond coats [34]. In the proposed model several stress influencing factors are discussed: mismatch of thermal expansion coefficients, martensitic transformation of $\beta-\mathrm{NiAl}$ and creep relaxation.

The first factor arises due to different CTE in the bond coat and superalloy. Upon cooling both parts contract however differently and depending on the substrate's CTE either tensile or compressive stresses are generated in the coating. Chen et al. calculated the corresponding strain by using CTEs of $15.5 \cdot 10^{-6} /{ }^{\circ} \mathrm{C}$ and $16.3 \cdot 10^{-6} /{ }^{\circ} \mathrm{C}$ for the bond coat and substrate, respectively. In case of a negative $\Delta \alpha$ compressive stresses are obtained and vice versa.

$\varepsilon=\Delta \alpha \Delta \mathrm{T}=-0.8 \cdot 10^{-6} /{ }^{\circ} \mathrm{C} 1100^{\circ} \mathrm{C}=-0.088 \%$
In $\mathrm{NiAl}$ alloys with a high $\mathrm{Ni}$ content martensitic transformation occurs even at low cooling rates which is associated with reduction of volume. This process introduces tensile strains in the bond coat. Chen determined the introduced strain to be $\varepsilon=(0.7 \pm 0.1) \%[35]$.

The third factor discussed by Balint and Hutchinson is the reduction of stresses by power law creep. $\mathrm{B} 2-\mathrm{NiAl}$ is reported to have a low creep resistivity and thus at temperatures above $\sim 600^{\circ} \mathrm{C}$ this plastic deformation reduces generated stresses considerably. Typically, the higher temperature and stress the larger is the creep relaxation. All factors combined result in calculated tensile stresses of about $1.2 \mathrm{GPa}$ at room temperature as proposed in their model.

In the present $\mathrm{NiAl}$ bond coats similar mechanisms are expected to determine the stress state. However, the tensile relaxation strain of $-0.75 \%$ of as-coated state (sample A) is higher compared to the model. Additionally, relaxation strains of $0.64 \%$ after cycling in sample $\mathrm{C}$ are compressive instead of tensile as reported in literature [33]. Compressive strain at ambient temperatures cannot be covered by the model. Therefore different mechanisms are needed for explanation.

The CTE mismatch of the samples can be assumed to be similar to the one of Chen et al. due to a similar substrate and coating system. However, the measured compressive strains of $0.64 \%$ cannot be explained by the CTE mismatch induced strain only which results in much lower values (cf. eq 6).

Further, martensitic transformation requires high $\mathrm{Ni}$ content in the $\beta$-phase which is not found in the investigated bond coats. Only in $\mathrm{Ni}$ rich $\mathrm{NiAl}$ (Ni content $>61$ at.\%) it is likely to form martensite on cooling. This is consistent with the XRD measurements which show no evidence of the martensitic phase.

Formation of $\gamma^{\prime}$-phase is found only in sample $\mathrm{C}$ due to $\mathrm{Al}$ depletion during heat treatment whereas in sample A no other phases are detected (see Figure 7). Although, this depletion of Al and the consequential formation of $\gamma^{\prime}$ generates tensile strain in the bond coat [35]. However, during heating the $\gamma^{\prime}$ phase does not dissolve at the maximum temperature and thus the strains generated due to ongoing growth in every cycle vanish due to creep relaxation. Over several cycles strain formation is assumed to shrink due to reduced $\mathrm{Al}$ depletion and thus decreasing $\gamma$ ' transformation. Tensile strains due to newly formed $\gamma^{\prime}$ remain on the last cooling cycle.

Due to the small length scale of the FIB milling method short ranged stresses also have to be considered. Intergranular strains are expected to rise with increasing cooling temperatures. Above $\sim 600{ }^{\circ} \mathrm{C}$ grains creep to a relaxed microstructure and during cooling individual grains tend to contract but are prevented by compatibility constraints and tensile strain is built up. With increasing cooling temperature the strain increases but not spatially uniform since the grain rotation is important due to strong elastic anisotropy in NiAl. A quantitative estimation of strain is difficult since deformation in the individual grain depends on its neighbors

In summary, the proposed model by Balint and Hutchinson is not entirely able to explain the findings. In order to explain the substantial difference in strain in the as coated state (sample A), the model is extended to incorporate a mechanism on the micro scale namely intergranular mismatch. In case of the thermally cycled sample $\mathrm{C}$ the compressive strain can be explained by assuming a negative $\Delta \alpha$. Further measurements are needed to confirm and validate the proposed influencing factors in order to explain the observed results. 


\section{Conclusion}

In summary, it could be shown that mechanical properties of $\mathrm{NiAl}$ from bond coat systems like Young's modulus, hardness and fracture toughness are dependent on the local composition. Its variation can be the result of the initial bond coat deposition process or thermal cycling which leads also to substantial changes in internal stresses. In this work, new approaches are presented to measure the fracture toughness and internal stresses of real bond coats on a micrometer length scale by employing FIB milling. In the process, samples with varying $\mathrm{Ni}$ and $\mathrm{Al}$ content originating from different deposition methods and thermal cycling are examined.

The results show a drop of about $100 \mathrm{GPa}$ in Young's modulus from $\mathrm{Al}$ rich to $\mathrm{Ni}$ rich $\mathrm{NiAl}$. A minimum for stoichiometric $\mathrm{NiAl}$ in hardness of $3 \mathrm{GPa}$ and in fracture toughness of $1.4 \mathrm{MPa} \cdot \mathrm{m}^{1 / 2}$ is observed while a deviation from this composition yields to higher values. Al rich NiAl surpasses the $\mathrm{Ni}$ rich sample in hardness. However, the highest fracture toughness is found in Ni rich NiAl. Furthermore, the local residual stress measurements of the as coated sample show tensile stresses of $1.55 \mathrm{GPa}$. Whereas in the thermally cycled sample compressive stresses of $-0.33 \mathrm{GPa}$ were found. By means of a stress evolution model proposed by Balint et al. the stress value cannot be fully explained concerning its magnitude. However, extending the model with intergranular mismatch a full description of the findings is possible.

\section{Acknowledgements}

The work presented here was financially supported by the German Science Foundation (DFG) in the frame of DFG graduate school 1229 and the Federal Ministry of Education and Research (BMBF) in the frame of the WING project "Efficient Coatings". Kind regards to MTU Munich for providing the samples.

We thank J. Ast, J. Schaufler, F. Iqbal, C. Schmid and M. Korn for support and help in experimental and theoretical work.

\section{References}

[1] G.W. Goward. Surface and Coatings Technology, 108 109(0):73 - 79, 1998.

[2] G. Bergmann and H. Vehoff. Scripta Metallurgica et Materiala, 30(8):969-974, 1994.

[3] M. Eskner and R. Sandström. Surface and Coatings Technology, 165(1):71 - 80, 2003

[4] M. Arana Antelo, P.K. Johnson, K.M. Ostolaza, and J. Bressers. Materials Science and Engineering A, 247(12):40-50, 1998

[5] S. Wöllmer, S. Zaefferer, M. Göken, T. Mack, and U. Glatzel. Surface and Coatings Technology, 167(1):8396, 2003.

[6] O. Franke, K. Durst, and M. Göken. Materials Science and Engineering: A, 467(1-2):15 - 23, 2007.

[7] R. Darolia. JOM, 43(3):44-49, 1991.

[8] T.C. Totemeier, W.F. Gale, and J.E. King. Materials Science and Engineering A, 169(1-2):19-26, 1993.

[9] E.E. Affeldt. Journal of Engineering for Gas Turbines and Power, 121(4):687-690, 1999.

[10] E.E. Affeldt. Advanced Engineering Materials, 2(12):811813,2000

[11] W. C. Oliver and G. M. Pharr. Journal of Materials Research, 7(6):1564-1580, 1992.

[12] K. Durst, O. Franke, and M. Göken. In Superalloys 2004, pages 467-476, Champion, PA, 2004.
[13] F. Iqbal, J. Ast, M. Göken, and K. Durst. Acta Materialia, 60(3):1193-1200.

[14] F. Thome, M. Göken, and H. Vehoff. Intermetallics, 7(3):491-499, 1999.

[15] M. Göken, F. Thome, and H. Vehoff. Philosophical Magazine A, 82(17-18):3241-3250, 2002.

[16] H. Vehoff, P. Ochmann, M. Göken, and M. Grosse Gehling. Materials Science and Engineering A, 239-240(1-2):378385, 1997.

[17] K.-M. Chang, R. Darolia, and H.A. Lipsitt. Acta Metallurgica et Materialia, 40(10):2727 - 2737, 1992.

[18] L.M. Pike, Y.A. Chang, and C.T. Liu. Acta Materialia, 45(9):3709-3719, 1997.

[19] C. M. F. Rae and R. C. Reed. Acta Materialia, 49(19):4113 $-4125,2001$

[20] R. Fischer, G. Frommeyer, and A. Schneider. Materials Science and Engineering A, 353(1-2):87 - 91, 2003.

[21] B. G. Mendis and K. J. Hemker. Philosophical Magazine, 87(27):4229-4251, 2007.

[22] G.A. Bozzolo, R.D. Noebe, and F.B. Honecy. Intermetallics, 8(1):7-18, 2000.

[23] G. Frommeyer， R. Fischer， J. Deges， R. Rablbauer, and A. Schneider. Ultramicroscopy, 101(2-4):139-148, 2004.

[24] T. Davenport, L. Zhou, and J. Trivisonno. Phys. Rev. B, 59:3421-3426, 1999.

[25] G.E. Dieter. Mechanical metallurgy. McGraw-Hill, 1988.

[26] N. Rusovic and H. Warlimont. Physica Status Solidi (A) Applied Research, 44(2):609-619, 1977.

[27] J. Westbrook. J. Electrochem. Sot., 103:54, 1956.

[28] R.T. Pascoe and C.W.A. Newey. Metal Science Journal, $2: 138-142,1968$.

[29] N. Rusovic and H. Warlimont. Physica Status Solidi (A) Applied Research, 53(1):283-288, 1979.

[30] P. Nash and O. Kleppa. Journal of Alloys and Compounds, 321(2):228-231, 2001.

[31] M.R. Harmouche and A. Wolfenden. Materials Science and Engineering, 84:35-42, 1986.

[32] G. Bergmann and H. Vehoff. Materials Science and Engineering A, 192-193(Part 1):309 - 315, 1995.

[33] M. Watanabe, D.R. Mumm, S. Chiras, and A.G. Evans. Scripta Materialia, 46(1):67 - 70, 2002.

[34] D.S. Balint and J.W. Hutchinson. Journal of the Mechanics and Physics of Solids, 53(4):949 - 973, 2005.

[35] M.W. Chen, M.L Glynn, R.T. Ott, T.C. Hufnagel, and K.J Hemker. Acta Materialia, 51(14):4279-4294, 2003.

\section{Appendix}

In order to calculate the direction cosines $l, m, n$, which accommodate the grain orientation in Bunge form, the rotation matrix $A$ is needed. The basic rotations are described by eq. 7 . Multiplying the matrices $Z_{2} \times Z_{1}$ result in $A$ (cf. eq. 8).

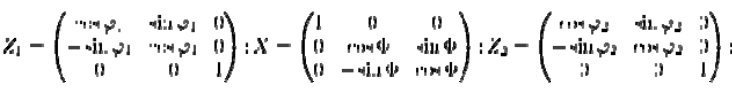

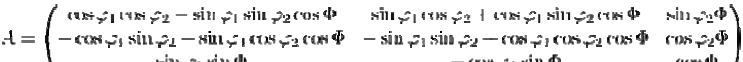

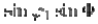

$$
\begin{aligned}
& \text {-(x) }
\end{aligned}
$$

The columns of Matrix $A$ represent the direction cosines for the sample directions $x, y$ and $z$ which corresponds to rolling, transverse and normal direction. Here, the transverse direction is used. 